\title{
Optimal Portfolios Including Credit Bonds and Derivatives: A Latest Research Review
}

\author{
Li Ma ${ }^{1, a}$, Bokai Zhang ${ }^{2, ~ b}$, Runchan $\mathrm{Li}^{3, \mathrm{c}}$ and Yue Wang ${ }^{4, \mathrm{~d}, ~}$ \\ ${ }^{1,2,3,4}$ College of Economics, Sichuan Agricultural University, Chengdu, China \\ amali980816@163.com, bzhangbokai@stu.sicau.edu.cn, 'wlx79798@163.com, \\ 'wangyue_001@163.com \\ ${ }^{*}$ Corresponding author
}

Keywords: Structural model, Reduced-form model, Hybrid model, Optimal portfolio.

\begin{abstract}
Referring to the relevant literatures and theories, this paper summarizes and combs many scholars' viewpoints related to optimal portfolios with credit bonds and derivatives. Due to the fact that asset pricing is the basis of asset portfolio, this paper expounds the pricing and optimal portfolio problems containing these credit products under structural, reduced-form and hybrid models respectively. Although the studies of structural and reduced-form models have been matured, there still exist many defects. Hybrid model that combines the advantages of the two models mentioned above will become increasingly prevalent in the future.
\end{abstract}

\section{Introduction}

Credit risk is always a major problem that puzzles financial institutions, especially when the credit products such as credit bonds and derivatives are involved in portfolios. Because the price trajectory of credit products ought to been figure out accurately before the research of optimization. Based on structural, reduced-form and hybrid models, this paper combs the classic and latest pricing methods of financial products including all kinds of credit products firstly. And then based on the dynamic price trajectory of these credit products, the paper summarizes the latest researches of optimal allocation of credit products under structural, reduced-form and hybrid models.

\section{Pricing research}

\subsection{Pricing of credit bonds}

The section below will review the relevant researches of pricing under structural, reduced-form and hybrid models respectively.

\subsubsection{Structural model}

The Pricing of credit bonds based on structural model originates from Merton [1]. Within the framework of Merton model, the market is complete, and only credit risk is included in the bond spread. Default occurs as the market value of the company's assets is lower than the book value of the debt at the maturity date of the debt. The market value of the company's assets satisfies the equation below:

$$
\mathrm{dA}_{\mathrm{t}}=\mu \mathrm{A}_{\mathrm{t}} \mathrm{dt}+\sigma \mathrm{A}_{\mathrm{t}} \mathrm{dw}_{\mathrm{t}}
$$

Merton proposes for the first time that the option pricing formula can be used to calculate the default probability. A company defaults when its value falls below a certain threshold. According to the BS formula, the equity value (E) and market value (D) of corporate debt can be expressed as follows:

$$
\begin{gathered}
\mathrm{E}(\mathrm{A}, \mathrm{T}, \sigma, \mathrm{r}, \mathrm{F})=\mathrm{A} \Phi\left(\mathrm{h}_{1}\right)-\mathrm{Fe}^{-\mathrm{rt}} \Phi\left(\mathrm{h}_{2}\right) \\
\mathrm{D}=\mathrm{A}-\mathrm{E}=\mathrm{Fe}^{-\mathrm{rt}} \Phi\left(\mathrm{h}_{2}\right)+\mathrm{A} \Phi\left(-\mathrm{h}_{1}\right)
\end{gathered}
$$

Subsequently, some scholars extend the Merton model, holding the opinion that default can occur at any time, which can be traced back to [2,3]. Varenne proposes that the default threshold is fixed 
value discounted by the risk-free rate before the maturity of the bond [4]. Liang, Bao and Zeng study the pricing of defaultable and redeemable corporate bonds with the risk of credit grade migration, considering the impact of credit changes on the pricing of financial products [5]. Yang constructs the financial bond portfolio by using the structural method, and deduces the bond pricing formula under the mixed jump-diffusion model by solving the stochastic partial differential equation [6].

\subsubsection{Reduced-form model}

Unlike the structural model, the reduced-form model is not based on the value of the company. In fact, this model is more general than structural model, because they could describe sudden default in a simple way. The reduced-form model can be traced back to [7-9]. In this model, default obeys a stochastic process (generally assumed to be Poisson process), and the probability of default is determined by a certain intensity, so it is also called strength model.

The reduced-form model avoids modeling unobservable corporate values, but treats the default process as a jump process. Define the time of default $r$ as never timely:

$$
\tau=\inf \left\{t: \int_{0}^{t} h(s) d s \geq E\right\}
$$

The default process is usually defined as a jump process.

\subsubsection{Hybrid model}

Recently, some scholars including Madan, Uneal and Daydov have combined structural and reduced-form models. The simplified model with the characteristic is called a hybrid model. In the hybrid model, default is still unpredictable. However, when the total value of corporate assets reaches a certain critical value, the likelihood of default increases rapidly. In the existing literatures, there are few researches on hybrid model, including CIR model and Vasicek model [10-13].

For the sake of simplicity of the model, the above scholars assume that the recovery rate and the probability of default are independent and the recovery rate is constant. Pan and Xiao establish a corporate bond pricing model with negative correlation between random recovery and default intensity [14]. Recently, they study the pricing problem of corporate bonds with dynamic default boundary under the hybrid model [15].

\subsection{Pricing of credit derivatives}

Currently, most of the literatures mainly adopt structural and reduced-form model to study the pricing of credit derivatives. Campbell and Tasksler propose a structural model to link the price of credit risk with the value of equity [16]. By means of the non-inter-temporal random fluctuation jump model, Chiarella, Maina and Sklibosios find that the price of a single name CDS is an exponential affine function under the condition of finite dimension [17].

Bi proposes that the most important variable is conditional prepayment ratio (CPR) while studying mortgage loans under the reduced-form model. Chen and Qin adopt single factor Gaussian Copula model to depict counterparty default risk, and obtain CDS pricing with default correlation [18]. Yu and Li use hierarchical Copula model to simulate the counterparty risk of bilateral transactions [19]

\section{Optimal portfolio research}

Portfolio optimization problem originates from Markowitz's mean-variance theory. This theory aims to distribute investors' wealth among different kinds of assets, so as to achieve the goal of diversifying risks and increasing profits. As the underlying assets of the portfolio expand to high-yield, high-risk bonds, the liquidity problem of bonds becomes more prominent. Once a company defaults, which will cause huge losses for investors. It can be seen that credit risk is a factor that cannot be ignored in portfolio optimization.

\subsection{Portfolio selection with credit bonds}

\subsubsection{Structural model}

Korn and Kraft, Kraft and Steffensen pioneer the optimal investment strategy for credit bonds [20,21]. 
They use a structural model to price credit bonds, with flexibility and duration as control variables. The optimal investment strategy is obtained by solving the HJB equation. However, the structural model has a disadvantage that the pricing of credit bonds is based on the known value of the company. While the general investors cannot often observe the company value, which results in that it is difficult to estimate the parameters with actual data. Therefore, the portfolio strategy obtained under this framework lacks practicality.

\subsubsection{Reduced-form model}

In view of the shortage of pricing under structural model, large number of scholars begin to study this problem under the framework of the reduced-form model. Walder studies how investors optimally allocate treasury and credit bonds under stochastic interest rates [22]. Hou and Jin discuss how stochastic control methods achieve optimal asset allocation between stocks, bank deposits, and credit bonds under fixed-rate and stochastic interest rates, giving an analytical solution to the optimal investment strategy [23,24]. Wang and Meng study the optimal portfolio of credit bonds when the interest rate obeys the CIR model [25]. Meindl and Primbs abandon the market friction-free assumption, introduce transaction costs in the model, and apply the rolling time domain control and Monte Carlo simulation to solve the investor's optimal holding of the credit bonds [26]. In order to solve the optimal investment strategy of defaultable rights, Biagini and Cretarola propose the local risk minimization method [27].

\subsubsection{Hybrid model}

Despite the apparent difference between the structural and reduced-form models, researchers notice the connection between them, trying to find a new model through unifying the two models. Lakner and Liang use a hybrid model to price credit bonds and obtain the optimal investment strategy for credit bonds through the martingale approach under fixed interest rates [28]. Gauthier, Boudreault and Thomassin present a framework, in which many structural credit risk models can be made hybrid by randomizing the default trigger, while keeping the capital structure intact [29].

\subsection{Portfolio with credit derivatives}

The credit derivative, which is a financial contract that separates the most traditional types of credit risk from other risk and can be transferred from one party to another. Therefore, it can hedge credit risk effectively to build a portfolio with credit assets such as credit bonds. However, compared to the pricing of credit bonds, academics currently have less researches on portfolios with credit derivatives. Papenbrock, Rachev and Höchstötter apply a structural model with $\alpha$-Stable distributions to research price calibration and hedging by involving credit derivatives [30]. Liang adds a fuzzy random theory to the combined credit derivatives based on the structural and reduced-form models in his doctoral thesis respectively [31]. Bo and Capponi model contagion risk among the reference entities in the portfolio by using a reduced-form model with interacting default intensities, and consider the optimal portfolio problem of a power investor who wishes to allocate his wealth between several credit default swaps (CDSs) and a money market account [32].

\section{Summary}

At present, the academic research on structural model has become mature. Most scholars consider improving the reduced-form model, such as introducing the relevance of default. In addition, some scholars discover that there are some disadvantages both in structural and reduced-form models. Therefore, they consider combining the two models to a more reasonable model, which is called hybrid model. There is still less research under the framework of hybrid model, which may be a hot issue of future research. As far as the research on credit derivatives is concerned, most of the literatures indicate that the current researches still focus on the pricing level. The research on building credit portfolios including credit derivatives is relatively rare but can be further developed in the future.

In China, the bond market is developing rapidly since 2007. Due to the fact that the data of financial market is insufficient to support relevant empirical research, the structural characteristics of 
bonds are still in a blank state. Therefore, it will become a prevalent issue to study the pricing and portfolio of credit bonds and derivatives.

\section{Acknowledgment}

This research was financially supported by and the Sichuan Provincial College Students Innovation Training Program (Item No. S201910626104) and the Shuangzhi Plan for Discipline Construction of Sichuan Agricultural University (Item No.1921993408).

\section{References}

[1] R. Merton, On the Pricing of Corporate Debt: the Risk Structure of Interest Rates, Journal of Finance, vol. 29, pp. 449-470, 1974.

[2] J. Cox, and F. Black, Some effects of bond indenture provisions, The Journal of Finance, vol. 31(2), pp. 351-367, 1976.

[3] F. Longstaff, and E. Schwartz, A simple approach to valuing risky fixed and floating rate debt, The Journal of Finance, vol. 50(3), pp. 798-819, 1995.

[4] B. F. D. Varenne, Valuing risky fixed rate debt: an extension, J Financ Quant Anal, vol. 32(2), pp 239-248, 1997.

[5] J. Liang, J. L. Bao, and C. K. Zeng, Pricing on a defaultable and callable corporate bond with credit rating migration under the structure framework, Journal of Systems Engineering, vol. 33(06), pp. 793-800+822, 2018.

[6] C. Q. Yang, A study on the pricing and default probability of financial bonds of a class of fund companies under the mixed jump-diffusion model, Systems Engineering, vol. 36(02), pp.16-28, 2018.

[7] P. Arzner, and E. Delbaen, Default risk insurance and incomplete markets, Mathematical Finance, vol. 5(3), pp. 187-195, 1995.

[8] R. Jarrow, and S. Turnbull, Pricing derivatives on financial securities subject to credit risk, Journal of Finance, vol. 50(1), pp. 53-85, 1995.

[9] D.B. Madan, and H. Unal, A two- factor hazard rate mod-el for pricing risky debt and the term structure of credit spreads, Journal of Financial and Quantitative Analysis, vol. 35(1), pp. 43-65, 2000 .

[10] D. Duffie, and D. Lando, The term structure of credit spreads with incomplete accounting information, Econometrica, vol. 69(3), pp. 633-664, 2001

[11] L. Cathcart, and L. Eijahel, Pricing defaultable bonds: A middle-way approach between structural and reduced-form models, Quantitative Finance, vol. 6(3), pp. 243-253, 2006.

[12] Y. S. Bi, Pricing of credit derivatives, Shanghai: Tongji University, 2008

[13] F. S. Emmanuel, and E. O. Helen, On the hybrid model for the valuation of credit risk, Applied and Computational Mathematics, vol. 3(1), pp. 8-11, 2014.

[14] J. Pan, and Q. X. Xiao, Pricing defaultable bonds with stochastic recovery under a hybrid model, Engrg Math,vol. 36(6), pp. 631-650, 2016.

[15] J. Pan, and Q. X. Xiao, Pricing corporate bond with dynamic default barrier based a hybrid model, Chinese J Appl Probab Statist, vol. 35(1), pp. 28-38, 2019.

[16] J. Y. Campbell, and G. B. Tasksler, Equity Volatility and Corporate Bond Yields, Journal of Finance, vol. 11, pp. 2321-2349, 2003. 
[17] C. Chiarella, S. C. Maina, and C. N. Sklibosios, Credit derivatives pricing with stochastic volatility modic. inuels. International, Journal of Theoretical and Applied Finance, vol. 16(4), 2013.

[18] Z. S. Chen, and X. Z. Qin, Valuation of CDS under Three Scenarios of Default Correlation based on the Simulation Analysis of Single Factor Copula Model, Journal of Systems \& Management, vol. 26(03), pp. 512-517, 2017.

[19] N. X. Yu, and J. Z. Li, Research on CDS pricing based on hierarchical Copula, Journal of Central University for nationalities (Natural Science Edition), vol. 26(03), pp. 91-96, 2017.

[20] R. Korn, H. Kraft, Optimal portfolios with defaultable securities: a firm value approach, International Journal of Theoretical and Applied Finance, vol. 17(7), pp. 793-819,2013.

[21] H. Kraft, M. Steffensen, Portfolio problems stopping at first hitting time with application to default risk, Mathematical Methods of Operations Research, vol. 63(10), pp.123-150, 2005.

[22] R. Walder, Dynamic allocation of treasury and corporate bond portfolios, FAME Research Paper, Switzerland, 2002.

[23] Y. Hou, and X. Jin, Optimal investment with default risk, FAME Research Paper, Switzerland, 2002.

[24] Y. Hou, Integrating market risk and credit risk: A dynamic asset allocation perspective, Working Paper, Yale University, 2003.

[25] L. F. Wang, and Q. X. Meng, Optimal Portfolio with Default Risk under Stochastic Interest Rate, Journal of Fudan University (Natural Science Edition), vol. 44(3), pp: 382-387, 2005.

[26] P. Meindl, and J. Primbs, Corporate bond portfolio optimization with transaction costs, Working Paper, Stanford University, 2006.

[27] F. Biagini, and A. Cretarola, Quadratic hedging methods for defaultable claims, Applied Mathematics and Optimization, vol. 56(3), pp: 425-443, 2007.

[28] P. Lakner, and W. Liang, Optimal investment in a defaultable bond, Mathematics and Financial Economics, vol. 1(3), pp: 283-310, 2008.

[29] G. Gauthier, M. Boudreault, and T. Thomassin, Credit Spreads, Recovery Rates and Bond Portfolio Risk Measures in a Hybrid Credit Risk Model, SSRN Electronic Journal, vol. 9(3), 2012.

[30] J. Papenbrock, S. T. Rachev, and M. Höchstötter, Price calibration and hedging of correlation dependent credit derivatives using a structural model with $\alpha$-stable distributions, Applied Financial Economics, vol. 19(17), pp:1401-1416, 2009.

[31] W. Liang, Research on pricing model of cashless flow credit derivatives in fuzzy random environment, Southeast University, 2016.

[32] L. Bo, and A. Capponi, Optimal investment in credit derivatives portfolio under contagion risk, Mathematical Finance, vol. 26(4), pp: 785-834, 2016. 